\title{
OTOMASI PADA MODUL SISTEM PENGUMPAN BERBASIS SEQUENTIAL FUNCTION CHART
}

\author{
Hary Respati Agus Sugiharto ${ }^{1}$, Agus Halim² dan Didi Widya Utama ${ }^{3}$ \\ Jurusan Teknik Mesin, Fakultas Teknik Universitas Tarumanagara \\ e-mail: hary_respati29@yahoo.com¹, agushalim@mm.co.id ${ }^{2}$,didiu@ft.untar.ac.id³
}

\begin{abstract}
Abstrak: Era globalisasi ini, mesin sistem manual dibiarkan dan diubah oleh mesin sistem otomatis untuk membantu operasi manusia. Dengan demikian makalah ini akan menjelaskan tentang bagaimana objek kerja dalam distribusi otomatis dibuat khusus untuk modul pengumpan (stasiun makan dan stasiun pengangkat) yang dibuat secara modular. Stasiun pakan dalam bentuk papan yang digerakkan oleh pneumatik tanpa batang dan berfungsi sebagai tempat kerja pendorong dimana di angkat sekrup untuk melanjutkan kerja benda ke stasiun berikutnya. Stasiun pengangkat berbentuk palet di lantai 3 yang digerakkan dengan motor DC gerak sudut yang diubah oleh sekrup timah menjadi gerakan linier untuk menyesuaikan ketinggian. Semua proses distribusi ini dikendalikan oleh PLC (Programmable Logic Controller) dalam kapasitas 26 I / O (16 input dan 10 output). Salah satu bahasa pemrograman yang mudah dipelajari adalah Functional Block Diagram (FBD). Pada FBD, ada metode Sequential Function Chart (SFC) untuk menentukan urutan pekerjaan program. Hasilnya adalah mesin simulasi stasiun makan dan stasiun pengangkat dalam skala laboratorium yang dapat memberi makan benda kerja di stasiun berikutnya sepanjang gerak diagram setiap stasiun.
\end{abstract}

Kata Kunci: Otomasi, sistem distribusi, Programmable Logic Controller, Sequential Function Chart.

\begin{abstract}
This globalization era, manual system machines is left and changed by automatic system machines to help human's operation. Accordingly this papers will describe about how the working object in automatic distribution is made especially for feeder module (feeding station and lifting station) which is made in modular. Feeding station in form of board which is moved by a rodless pneumatic and function as thruster working object where in lifting screw to continue working object to next station. Lifting station in form of pallet in 3 storey which is moved by angular motion DC motor which is changed by lead screw to linear motion to adjust the height. All this distribution process is controlled by PLC (Programmable Logic Controller) in 26 I/O (16 input and 10 output) capacity. One of easy learning programming language is Functional Block Diagram (FBD). On FBD, there is Sequential Function Chart (SFC) method to set job sequence of program. The result is simulation machine of feeding station and lifting station in laboratory scale which can feed working object in next station along motion of diagram each station.
\end{abstract}

Keywords: Automation, distribution system, Programmable Logic Controller, Sequential Function Chart.

\section{PENDAHULUAN}

Pada era globalisasi ini, mesin-mesin kendali manual mulai ditinggalkan dan digantikan dengan mesin-mesin bersistem kendali otomasi yang bertujuan untuk membantu pekerjaan manuasia. Salah satu cara yang digunakan pada industri secara luas untuk berbagai keperluan kendali proses adalah Programmable Logic Controller (PLC). Kebutuhan untuk kontroler murah, fleksibel dan mudah yang telah menghasilkan pengembangan dari programmable logic controller dapat digunakan dengan cepat dan dalam berbagai macam aplikasi industri (Elsevier, 2004). Programmable Logic Controllers (PLC) adalah suatu sistem elektronik yang dirancang untuk industri yang menggunakan memori yang dapt diprogram sebagai fasilitas penyimpanan internal dari instruksi - instruksi untuk menjalankan fungsi - fungsi khusus seperti logika, pengurutan, waktu, dan aritmatika untuk mengontrol berbagai jenis mesin atau proses melalui input dan output digital dan analog (Bryan,1997). Salah satu bahasa pemrograman yang dapat digunakan dalam pemrograman PLC adalah bahasa Function Block Diagram (FBD) dan untuk mempermudah alur kerja dari pergerakan yang diinginkan dapat menggunakan sistem Sequential Function Chart (SFC). 


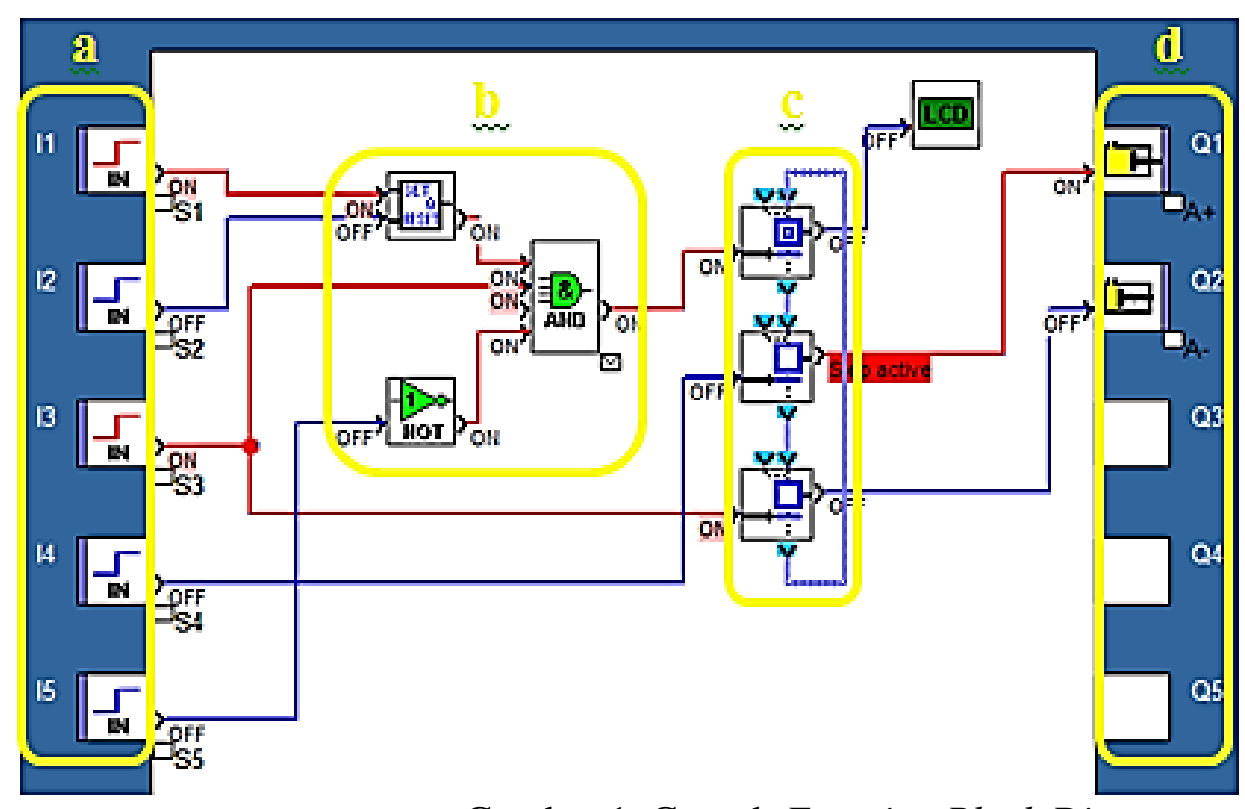

Keterangan gambar:

- a adalah tempat masukan function blocks

- b adalah function blocks

- c adalah sequential function chart

- d adalah tempat keluaran function chart

Gambar 1. Contoh Function Block Diagram

Salah satu sistem otomasi yang sering dipakai dalam industri adalah sistem distribusi, yang meliputi: Stasiun Pendorong, Stasiun Pengangkat (penyimpanan sementara), Stasiun Penyanggah, Stasiun Penyortiran. Pada penelitian ini akan membahas tentang simulasi otomasi distribusi benda kerja dikhususkan pada modul pengumpan (stasiun pendorong dan stasiun pengangkat) yang disusun secara modular dalam skala laboratorium.

Pada dasarnya stasiun pendorong adalah stasiun pada penyediaan dan produksi secara otomasi. Stasiun pendorong dapat dihubungkan dengan stasiun lainnya secara mekanik maupun elektronik dengan teknologi komunikasi yang terintregasi sehingga memberikan banyak kemungkinan kombinasi. Lalu pada stasiun pengangkat memiliki pengertian yang sama dengan tempat penyimpanan sementara, sehingga stasiun pengangkat ini berhubungan dengan stasiun pendorong. Benda yang terdapat pada stasiun pengangkat akan terdorong oleh silinder pnumatik pada stasiun pendorong dan diteruskan menuju stasiun berikutnya. Pada stasiun pengangkat menggunakan roadless yang terdapat pada Laboratorium Hidrolik dan Pneumatik Universitas Tarumanagara belum berjalan dengan baik karena tidak akurat berhentinya stasiun pengangkat tersebut, maka dari itu akan mengganti stasiun pengangkat yang sebelumnya menggunakan roadless menjadi lead screw dengan harapan akan lebih optimal dan lebih akurat untuk sistem pengangkat tersebut. Skets untuk pembaharuan sistem pengangkat tersebut dapat dilihat pada Gambar 2.

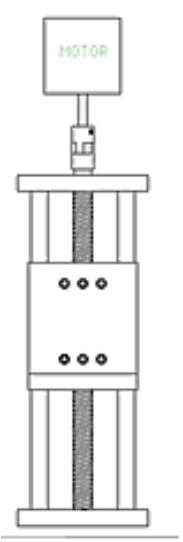

(a)

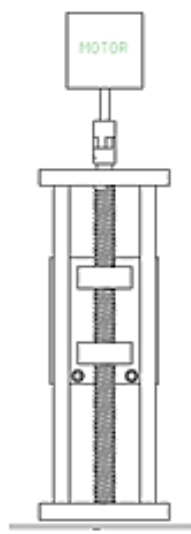

(b)

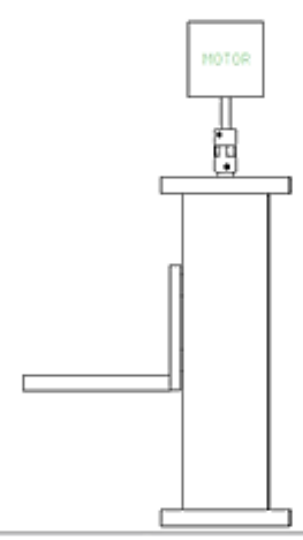

(c)

Gambar 2. Skets stasiun pengangkat menggunakan lead screw (a) tampak depan, (b) tampak belakang, (c) tampak Samping 


\section{METODE PENELITIAN}

Dalam proses perancangan Otomasi Pada Modul Sistem Pengumpan Berbasis Sequential Function Chart ini digunakan metode studi literatur, membangun stasiun pengangkat dengan leadscrew, lalu memprogram ulang modul sistem pengumpan dengan Sequential Function Chart (SFC).

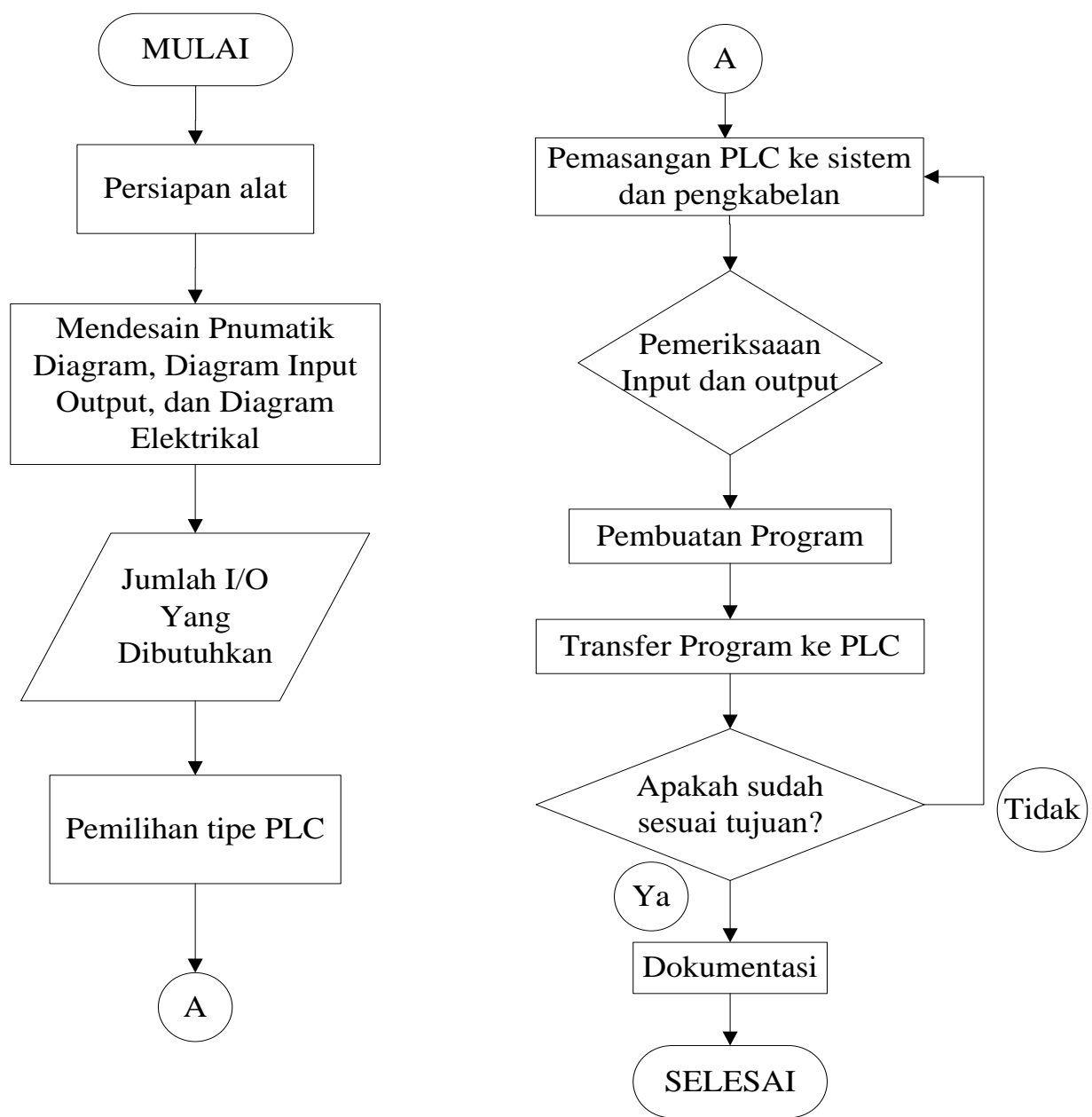

Gambar 3. Diagram alir metode penelitian

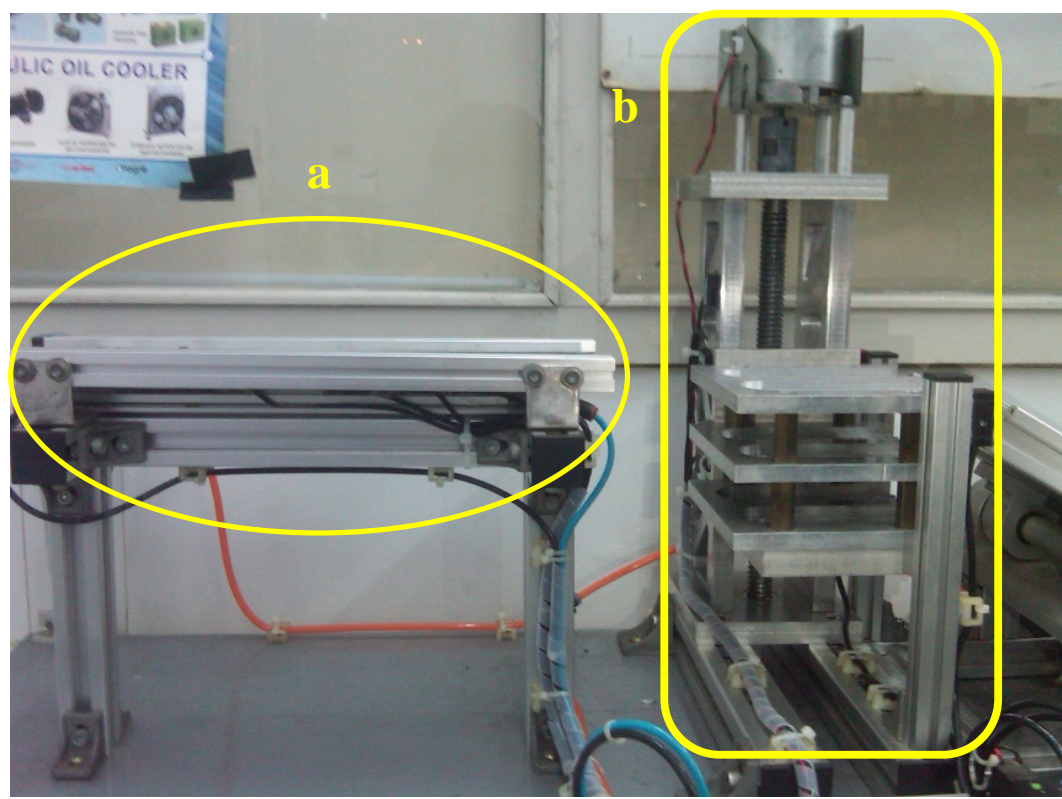

Gambar 4. (a) Stasiun pendorong, (b) stasiun pengangkat 
Modul pengumpan yang terdiri dari stasiun pendorong (feeding) dan pengangkat (lifting) dapat bekerja secara manual maupun otomatis dan sekuensial berdasarkan program yang dibuat.

Stasiun pendorong beroprasi untuk mendorong benda kerja berjumlah 6 yang tersusun 3 baris setiap lantai pada rak stasiun pengangkat agar benda kerja dapat distribusikan ke stasiun berikutnya. Stasiun pendorong menggunakan silinder rodless pneumatik yang menggunakan 4 unit sensor proximity sebagai pengatur posisi yaitu sensor PF 1, PF 2, PF 3, dan PF 4. Sensor PF 1 adalah posisi awal untuk mendorong. PF 2 adalah batas gerakan mendorong untuk benda kerja pada baris pertama yang terletak pada rak stasiun pengangkat, SF 3 adalah batas gerakan mendorong benda kerja baris ke dua, dan SF 4 adalah batas gerakan mendorong benda kerja pada baris ke tiga. Gerakan silinder stasiun pendorong diatur oleh katub solenoid 5/2 spring return. Diagram alir yang menjelaskan cara kerja stasiun pendorong dapat dilihat pada Gambar 5.

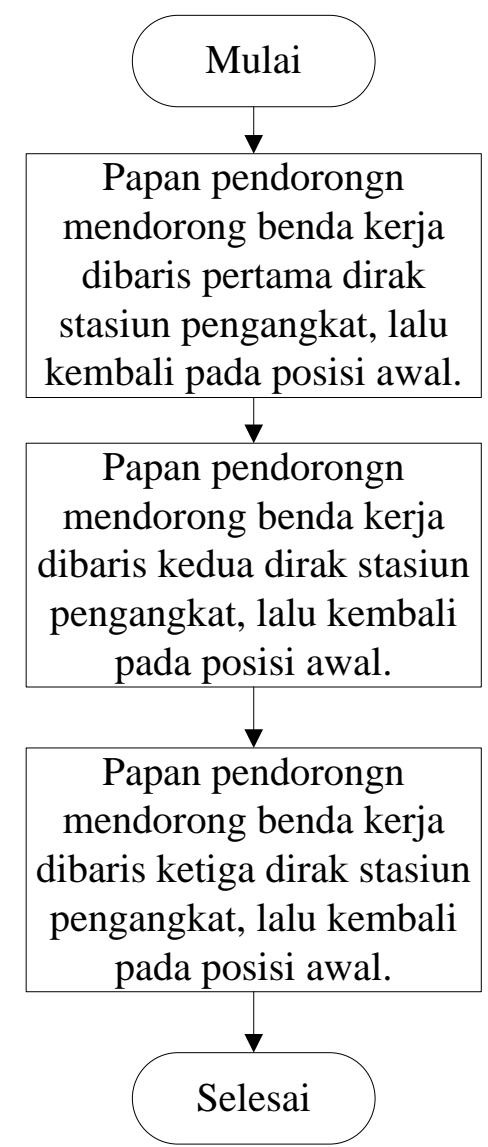

Gambar 5. Diagram alir cara kerja stasiun pendorong

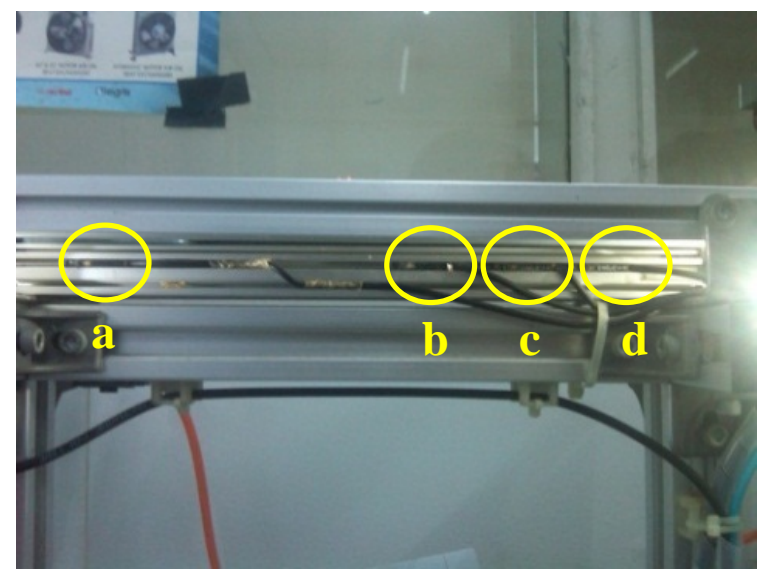

Keterangan :

- a adalah proximity feeding 1 (PF1)

- b adalah proximity feeding 2 (PF2)

- c adalah proximity feeding 3 (PF3)

- d adalah proximity feeding 4 (PF4)

Gambar 6. Sensor - sensor pada stasiun pendorong 


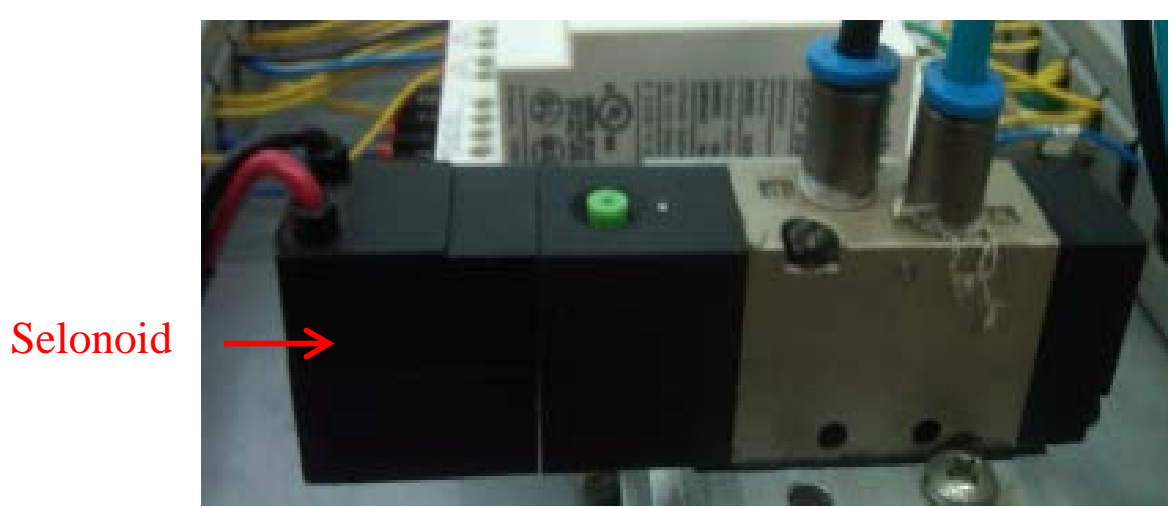

Gambar 7. Selonoid valve 5/2 spring return

Stasiun pengangkat sebagai penyimpanan sementara benda kerja yang berada pada rak tiap tingkat yang memiliki tiga tingkat dimana masing-masing tingkat menyimpan 6 buah benda kerja. Beroprasi untuk memposisikan rak agar benda kerja dapat didorong oleh stasiun pendorong agar benda kerja dapat distribusikan ke stasiun berikutnya. Stasiun pengangkat merupakan gerakan berputar motor DC dengan kecepatan putar $670 \mathrm{r} / \mathrm{min}$ yang dirubah oleh leadscrew menjadi gerakan lurus (naik dan turun) dengan pitch $4 \mathrm{~mm}$. Menggunakan 3 sensor proximity untuk mengatur posisi ketinggian rak yaitu PL 1, PL 2, PL 3 dan satu pasang sensor photoelectric sebagai pembaca keberadaan benda pada rak stasiun pengangkat yaitu Bd. PL 1 sebagai pengatur posisi rak tingkat pertama, PL 2 posisi rak tingkat ke 2, dan PL 3 posisi rak tingkat ke 3. Gerakan motor DC diatur oleh 2 unit relay. Diagram alir yang menjelaskan cara kerja stasiun pengangkat dapat dilihat pada Gambar 8.

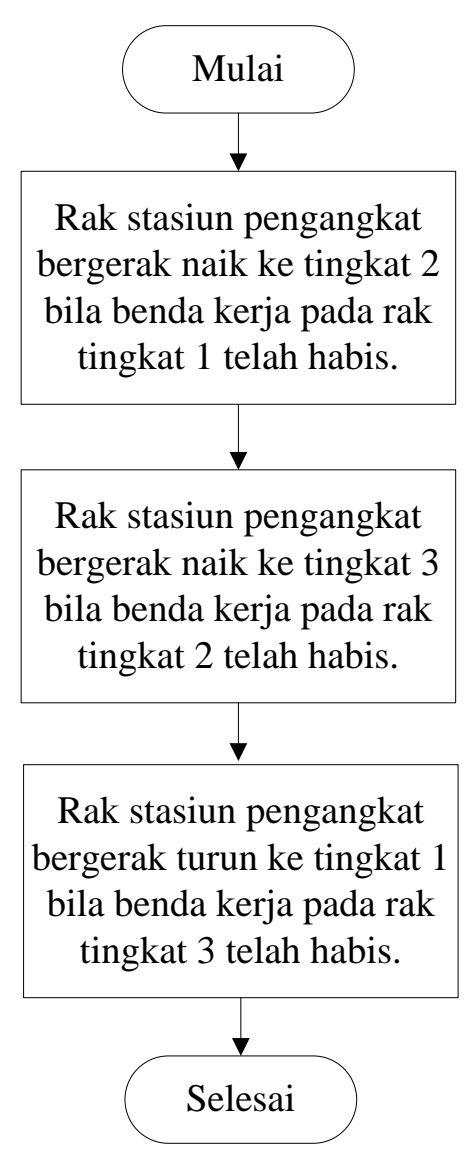

Gambar 8. Diagram alir cara kerja stasiun pengangkat 

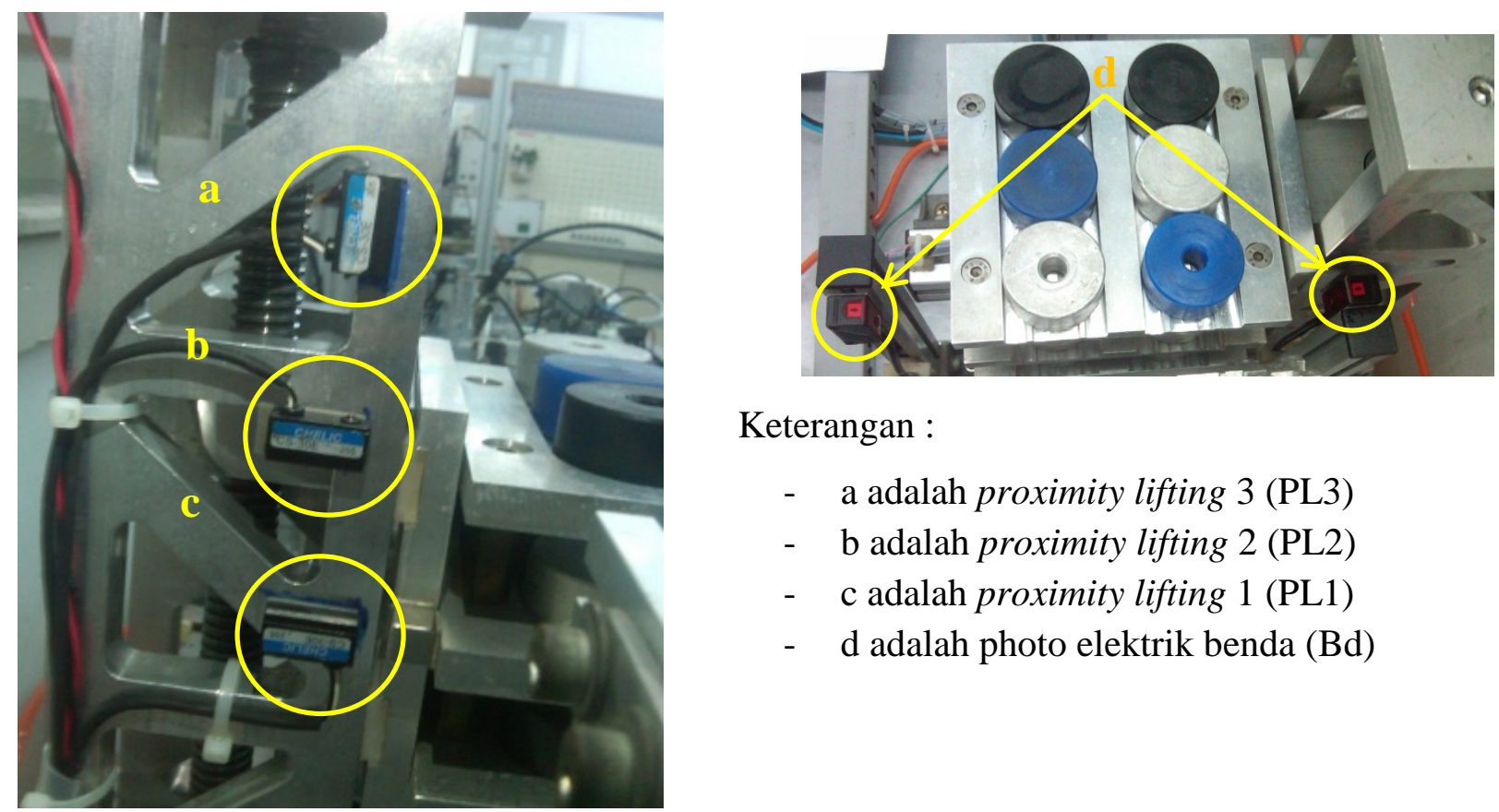

Keterangan :

- a adalah proximity lifting 3 (PL3)

- $\quad$ b adalah proximity lifting 2 (PL2)

- c adalah proximity lifting 1 (PL1)

- d adalah photo elektrik benda (Bd)

Gambar 9. Sensor - sensor pada stasiun pengangkat

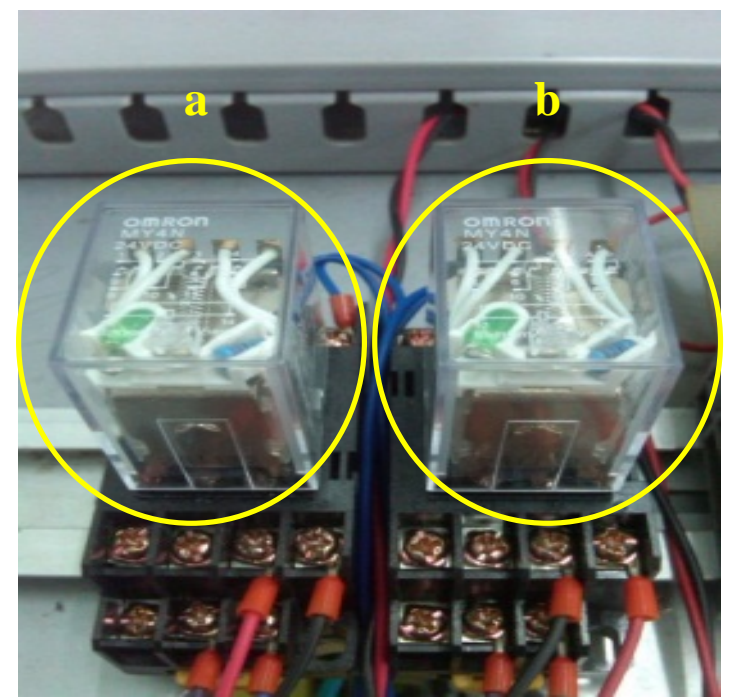

Keterangan :

- $\quad$ a adalah relay lifting naik

- b adalah relay lifting turun

Gambar 10. Relay stasiun pengangkat 


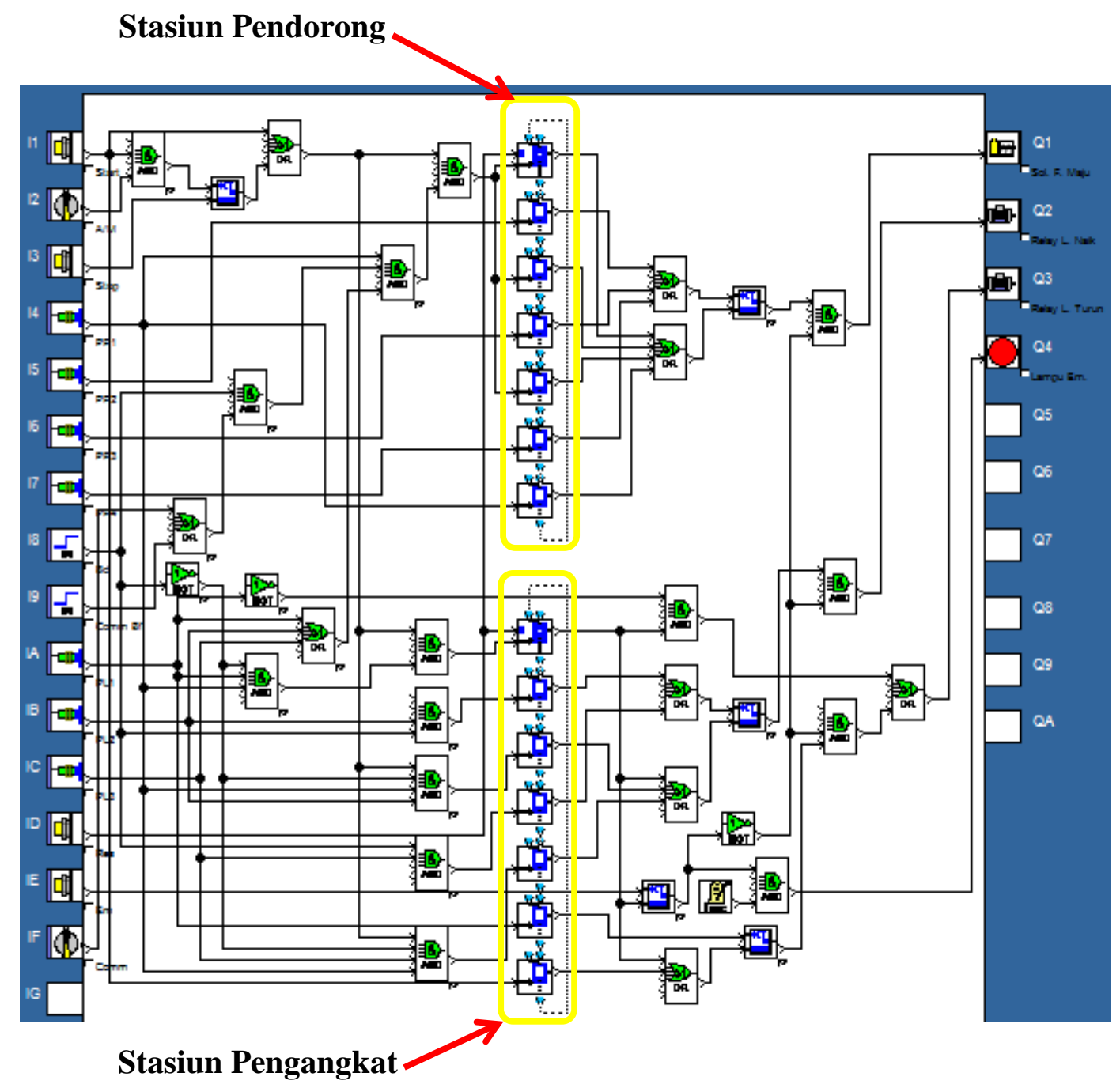

Gambar 11. Program modul pengumpan

\section{HASIL DAN PEMBAHASAN}

Langkah pengujian adalah melakukan simulasi pada software Zelio Soft 2, lalu memindahkan program ke dalam PLC, dan mengoprasikan modul. Maka didapat gerakan dari program yang telah dibuat yang diolah oleh PLC. 


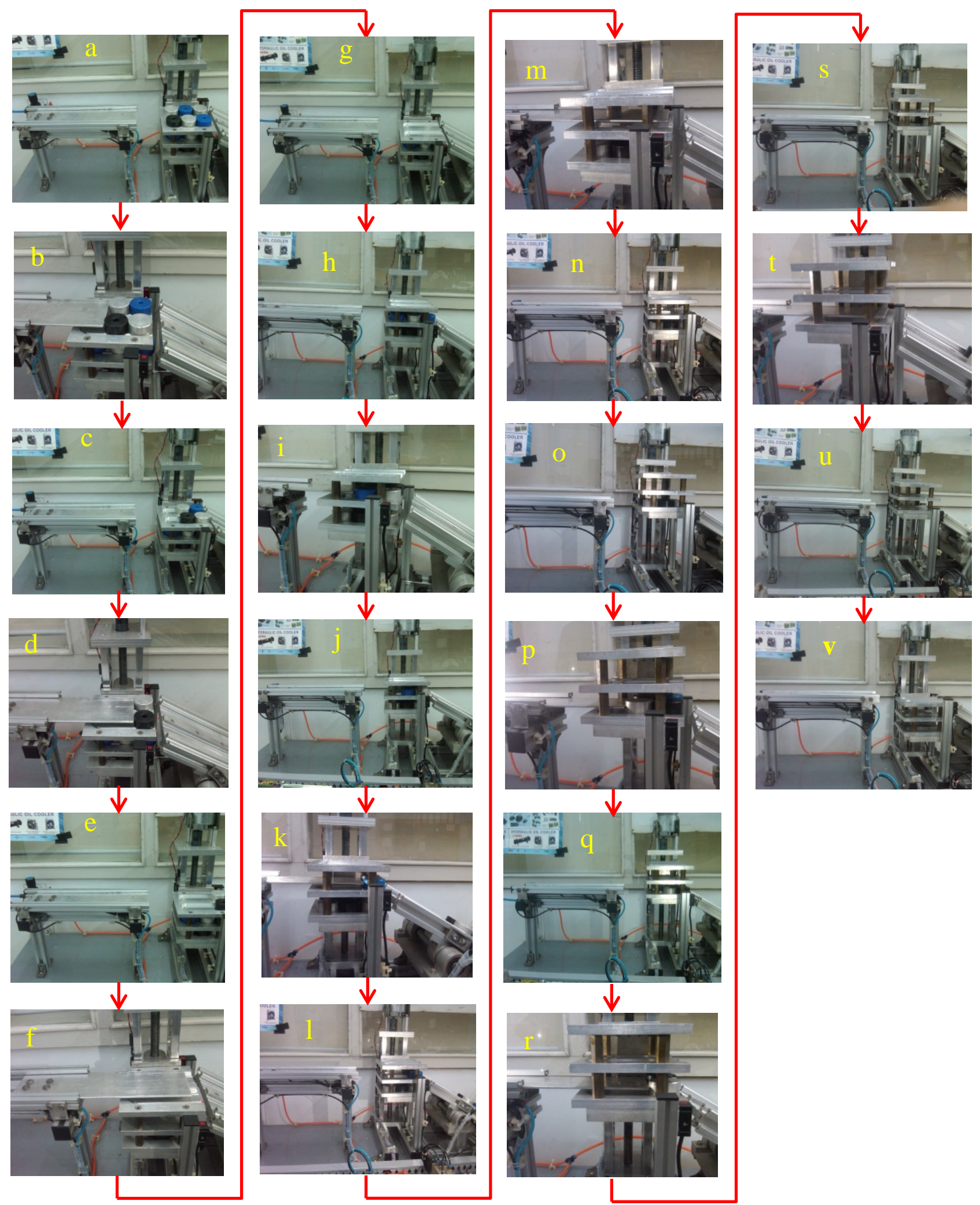

Gambar 12. Gambar yang menunjukan gerakan pengujian modul pengumpan

Keterangan :

a : Keadaan posisi awal untuk memulai proses kerja.

b : Papan stasiun pendorong mendorong benda kerja pada rak stasiun pengangkat dilantai pertama dan baris pertama.

c : Papan pendorong kembali ke posisi awal untuk menunggu perintah bila sinyal komunikasi dari stasiun penyanggah aktif. 
d : Papan stasiun pendorong mendorong benda kerja pada rak stasiun pengangkat dilantai pertama dan baris kedua.

e : Papan pendorong kembali ke posisi awal untuk menunggu perintah bila sinyal komunikasi dari stasiun penyanggah aktif.

$\mathrm{f}$ : Papan stasiun pendorong mendorong benda kerja pada rak stasiun pengangkat dilanti pertama dan baris ketiga.

g : Papan pendorong kembali ke posisi awal untuk menunggu perintah bila sinyal komunikasi dari stasiun penyanggah aktif.

$\mathrm{h}$ : Stasiun pengangkat mengangkat rak ke lantai dua.

i : Papan stasiun pendorong mendorong benda kerja pada rak stasiun pengangkat dilantai ke dua dan baris pertama.

j : Papan pendorong kembali ke posisi awal untuk menunggu perintah bila sinyal komunikasi dari stasiun penyanggah aktif.

$\mathrm{k}$ : Papan stasiun pendorong mendorong benda kerja pada rak stasiun pengangkat dilantai kedua dan baris kedua.

$\mathrm{l}$ : Papan pendorong kembali ke posisi awal untuk menunggu perintah bila sinyal komunikasi dari stasiun penyanggah aktif.

$\mathrm{m}$ : Papan stasiun pendorong mendorong benda kerja pada rak stasiun pengangkat dilantai kedua dan baris ketiga.

$\mathrm{n}$ : Papan pendorong kembali ke posisi awal untuk menunggu perintah bila sinyal komunikasi dari stasiun penyanggah aktif.

o : Stasiun pengangkat mengangkat rak ke lantai tiga.

p : Papan stasiun pendorong mendorong benda kerja pada rak stasiun pengangkat dilantai ketiga dan baris pertama.

q : Papan pendorong kembali ke posisi awal untuk menunggu perintah bila sinyal komunikasi dari stasiun penyanggah aktif.

$r$ : Papan stasiun pendorong mendorong benda kerja pada rak stasiun pengangkat dilantai ketiga dan baris kedua.

s : Papan pendorong kembali ke posisi awal untuk menunggu perintah bila sinyal komunikasi dari stasiun penyanggah aktif.

$\mathrm{t}$ : Papan stasiun pendorong mendorong benda kerja pada rak stasiun pengangkat dilantai ketiga dan baris ketiga.

u : Papan pendorong kembali ke posisi awal untuk menunggu perintah bila sinyal komunikasi dari stasiun penyanggah aktif.

$\mathrm{v}$ : Stasiun pengangkat menurunkan rak kembali ke posisi awal atau pada lantai pertama tetapi dalam keadaan tidak terisi benda kerja.

Diagram step untuk pengujian modul pengumpan dapat dilihat pada Gambar 13.

Pada pengujian modul pengumpan ini dilakukan sebanyak 5 kali dengan jumlah 18 benda kerja setiap pengujiannya. Pengujian yang dilakukan dan hasilnya dapat dilihat pada tabel berikut:

Tabel 1 Hasil pengujian modul pengumpan

\begin{tabular}{ccc}
\hline Pengujian & Bekerja Dengan Baik & Waktu satu siklus (detik) \\
\hline 1. & Ya & 22,72 \\
2. & Ya & 22,67 \\
3. & Ya & 22,69 \\
4. & Ya & 22,75 \\
5. & Ya & 22,84 \\
\multicolumn{2}{c}{ Rata-rata waktu satu siklus } & 22,73 \\
\hline
\end{tabular}


Berdasarkan pengujian modul pengumpan gerakan dapat berjalan secara sinkron dan tetap bersifat modular didapatkan total waktu rata-rata untuk keseluruhan gerakan 22,73 detik. Flow control pada silinder rodless stasiun pendorong untuk maju $24 \%$ dan untuk mundur 51,85 \%.

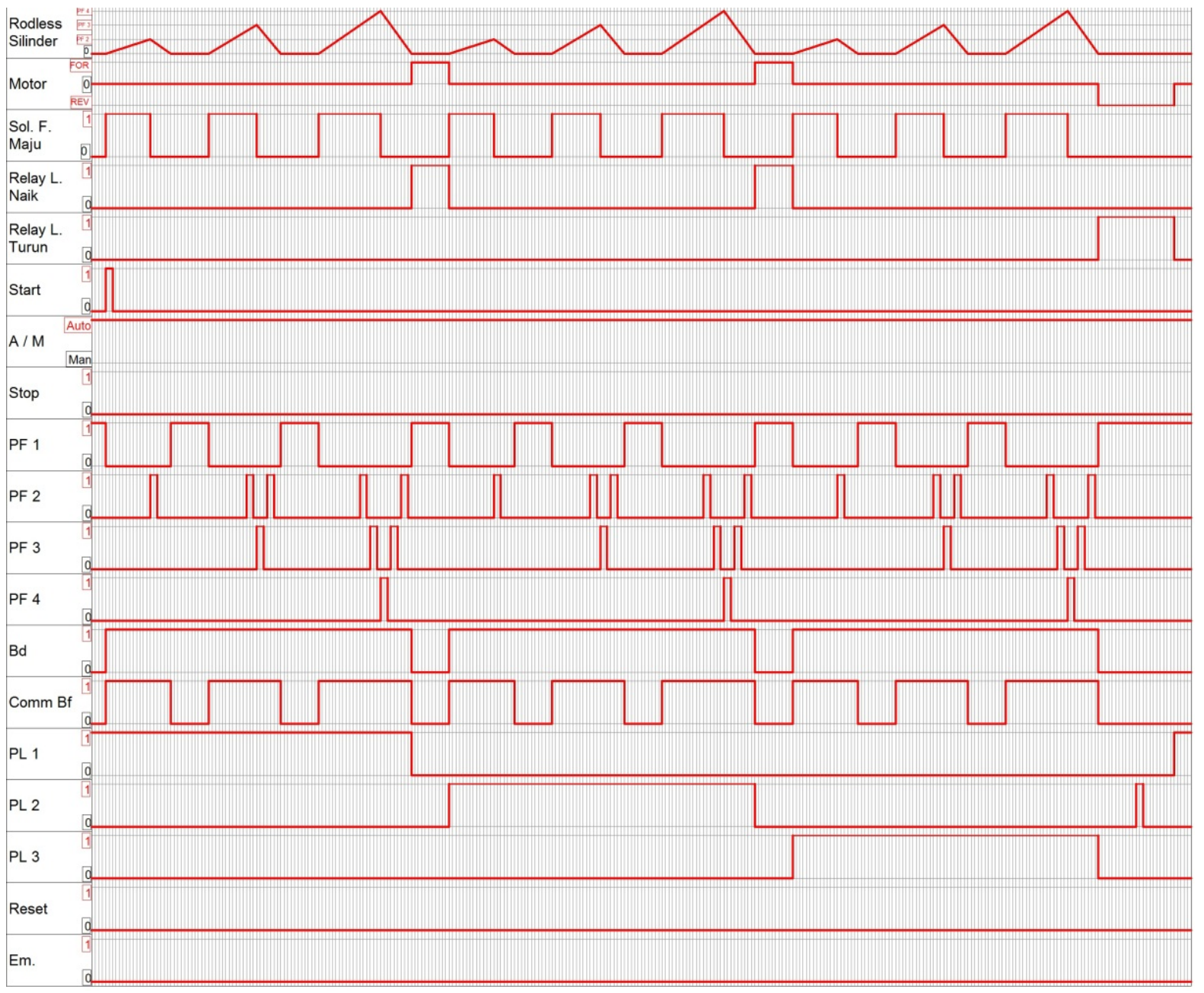

Gambar 13. Diagram step modul pengumpan

\section{KESIMPULAN}

Berdasarkan penelitian yang di lakukan maka dapat diambil kesimpulan sebagai berikut:

a. Program dan sistem yang dibuat dengan menggunakan bahasa pemrograman berbasis SFC (Sequential Function Chart) dapat bekerja dengan baik sesuai seperti yang direncanakan.

b. Modul pengumpan yang terdiri dari stasiun pendorong dan pengangkat dapat bekerja dengan sinkron dan secara modular, hal ini terlihat bahwa benda kerja dapat didistribusikan secara lancar.

c. Stasiun pengangkat telah memposisikan benda kerja pada setiap rak dengan akurat sehingga spesimen dapat terdorong oleh stasiun pendorong dengan baik dan dapat terdistribusi pada stasiun selanjutnya.

d. Dari hasil pengujian, keseluruhan waktu satu siklus rata-rata modul pengumpan adalah 22,7 detik.

e. Dari hasil perhitungan, putaran motor DC yang digunakan adalah $670 \mathrm{r} / \mathrm{min}$ dengan leadscrew yang memiliki spesifikasi pitch $4 \mathrm{~mm}$ dan diameter luar $20 \mathrm{~mm}$. 


\section{DAFTAR PUSTAKA}

[1]. Aanajja's, “Pengertian Dan Perbedaan Sistem Mesin Hidrolik Dan Pneumatik,” (Online, Diakses Maret 2015) https://aanajja.wordpress.com/2012/04/25/pengertian-dan-perbedaansistem-mesin-hidrolik-dan-pneumatik/

[2]. Bryan, Programmable Controllers: Theory and Implementation, L.A. 1997. Second Edition. Atlanta: An Industrial Text Company Publication.

[3]. Elsevier, Introduction to PLC's, 2004. Burlintong: Elsevier Newnes.

[4]. Hackworth, John.R dan Hackworth.F.D. Programmable Logic Controllers: Programming Methods and Applications, 2004. Virginia: Pearson/Prentice Hall

[5]. Khasawneh, Hussam. Introduction to PLC and Ladder Logic, 2009. Amman: Faculty of Engineering and Technology Universitas Of Jordan.

[6]. Khurmi, R.S. dan J.K. Gupta. A Textbook of Machine Design. New Delhi: Eurasia, 2005.

[7]. Ngadi Permana, Ferdinan Hendra, Leonardus, “ Perancangan Konseptual Sistem Transfer Pada Processing Work Station”. Skripsi, Universitas Tarumanagara, Fakultas Teknik, Jakarta, 2001. 